International Journal of Engineering \& Technology, $7(2.31)(2018) 37-40$
International Journal of Engineering \& Technology
SPC
Website: www.sciencepubco.com/index.php/IJET
Research paper

\title{
Adaptive protection scheme for microgrids
}

\author{
C. Vaithilingam*, Himani Jain, Medha Ojha, Meghna Singh, J. Vijay Joseph Samuel \\ VIT University, Chennai. \\ *Corresponding author E-mail: vaithilingam.c@vit.ac.in
}

\begin{abstract}
Micro grids are gaining attention to become an integral part of traditional power system, due to their numerous technical benefits and their ability to improve power system reliability.Voltage regulation, reduction in Transmission and distribution losses, reduction in the need for transmission capacity addition etc are the few technical benefits of micrgrids with renewable energy sources. However, a protection scheme that suits a conventional power system will require a major revamp if micro grids need to be interfaced. The power generations of each renewable source, mode of operation of microgrids are the few important factors to be considered to fix the relay settings. The conventional over current protection scheme faces selectivity and sensitivity issues during the grid faults and the microgrid faults, since the fault current level is different in both the cases. Hence, electro mechanical and static relays may not be suitable for the protection of power systems with microgrids. The processor based relays with augmented intelligence, that is, a relaying scheme which can act according to the operating condition need to be developed. This paper proposes an adaptive protection scheme for power systems with microgrids. The proposed method in this paper is tested with a hardware prototype resembles the actual microgrid setup.
\end{abstract}

\section{Introduction}

Restructuring of power systems transforms the vertically integrated power system to horizontal structure[1]. The deregulation allows the Independent Power Producers (IPPs) to generate power and supply to consumers through bilateral contracts. The performance efficiency of renewable energy sources is in increasing trend and the technological developments in power electronic devices and circuits facilitate the effective power conversion topologies [2]. The technical, procedural and operational hindrances for the distributed generations are slowly disappearing; this facilitates the technical realization of microgrids [3-5]. The use of these systems may reduce power generation costs and transmission and distribution losses that incur in conventional power systems. However, there are certain limitations when protection of power system with microgridis concerned [6-8]. Due to the intermittent nature of the distributed generators used in micro grids the fault current may vary. In addition to this, the changing modes of connection i.e. Islanded and Grid-connected mode results in the variation of fault current $[9,10]$. Therefore, it is necessary to modify the conventional protection schemes or design new protection schemes.

This paper proposes Arduino based adaptive protection scheme using wireless communication. The proposed method is tested on a prototype with DC sources. The test result shows the operation of the relay is based on the operating condition of distributed energy sources and the mode of operation of the system. The dynamic conditions of the power system are handled effectively with the help of the proposed Adaptive Protection scheme. The proposed protection scheme provides a selective and fast protection through the use of wireless communication.

\section{Proposed method}

This paper proposes a method to change the relay setting dynamically with respect to operating conditions.The fault currents of the test system at all the possible operating conditions are obtained using conventional fault analysis. The operating conditions are represented using power generation and modes of operation. The Arduino processor is programmed using fault current values obtained for different operating conditions. The information such as generation level, load level and mode of operation will be communicated to Arduino processor through bluetooth communication. The information will be processed and the processor will decide whether it is a fault condition or not.

The proposed method is explained using the block diagram given in Figure 1. DG1 and DG2 are the two distributed energy sources. The loads are connected to DGs and an interface switch at the Point of Common Coupling is used to connect the microgrid to grid. If the PCC is open the system works in islanded mode and if PCC is closed it will operate in grid connected mode.

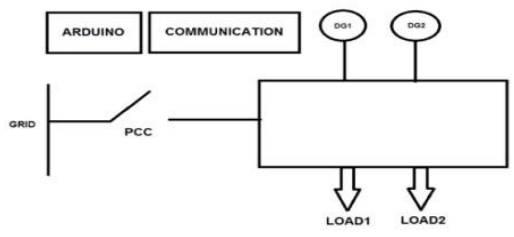

Figure 1: Overall block diagram

The prototype of the proposed method will be developed using three sources. namely, grid source and two DG's. The microgrid consists of two DGs will be connected to grid source through the point of common coupling (PCC). Fault analysis is performed using Simulink model of the power system. The fault currents changes according to the modes of operation. The Arduino Uno microcontroller is coded using the data obtained through fault 
analysis. The current values will be checked for the fault current conditions to control the switch accordingly. The relay settings need to be dynamically changed as per the operating modes. For this, the status of DGs and mode of operation needs to be sensed continuously. This is communicated to the processor through Bluetooth based communication system. This technique is used to open/close the PCC according to the dynamic fault currents that may arise. The information communicated to the processor will be processed and the prcessor act as a relay gets energised when the fault occurs and turns on the alarm.

The design and development of the adaptive protection scheme has been divided into three modules. These are as follows:
1. Simulation
2. Hardware Setup
3. Arduino coding

\section{Module 1 - Simulation}

The three phase fault analysis and unsymmetrical fault analysis are carried out to determinethe fault current using Simulink. The fault currents are categorized based on the operating modes, generation level and types of fault.

\section{Module 2- Hardware setup}

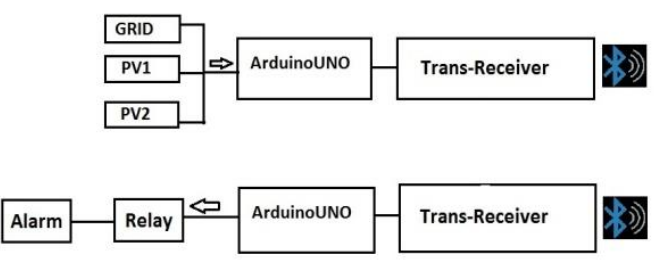

Figure 2: Hardware setup

Three Regulated Power Supply modules are employed to represent three sources namely, Grid source, Photo Voltaic source 1 PV1 (DG1) and Photo Voltaic source 2(DG2) PV2. The Arduino Uno microcontroller is coded to take the voltage values from the three sources and formulate current values to check for the fault current conditions. The fault current status is communicated from one microcontroller to another via Bluetooth modules. For the wireless communication two Bluetooth modules have been employed namely, Master and Slave. Depending upon the status, the second Arduino Uno microcontroller energizes the relay and consequently, controls the ringing of alarm.

\section{Wireless communication}

\section{Master bluetooth module circuit}

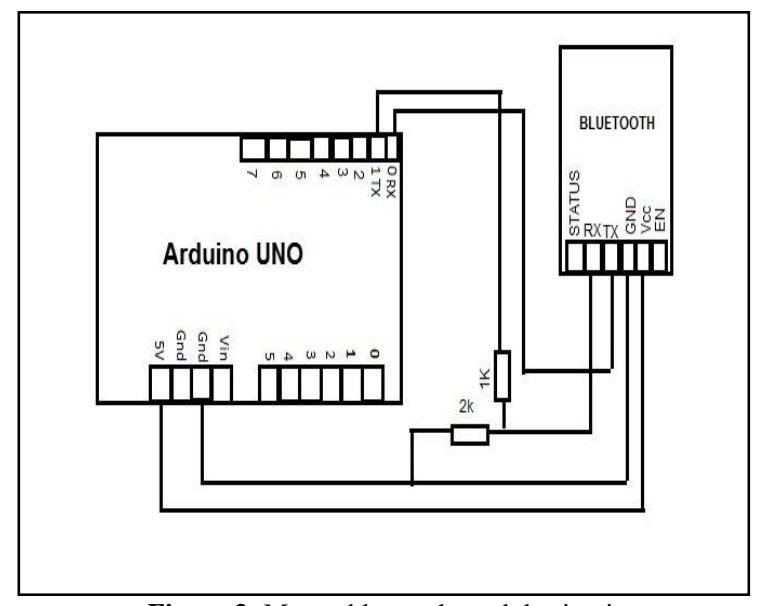

Figure 3: Master bluetooth module circuit

\section{Slave bluetooth module circuit}

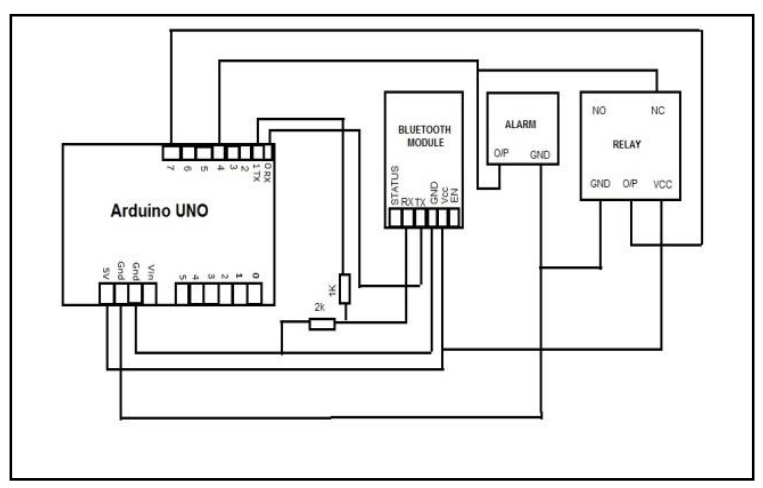

Figure 4: Slave bluetooth module circuit

\section{Module 3- Arduino coding}

\section{Algorithm}

Step 1: From the Simulation results Reference $1500 \mathrm{~A}=1 \mathrm{~V}$

Step 2: Three sources-

- $\mathrm{X}$ as grid source

- Y as PV1

- Z as PV2

Step 3: Decision making depending upon the combination of supplies(different modes):

\section{Grid connected mode}

$\mathrm{X}>=1 \mathrm{~V}$

Fault detected

PCC opens; alarm rings

\section{Islanded mode}

$\mathrm{Y}>=1.5 \mathrm{~V}, \mathrm{Z}>=1.5 \mathrm{~V}$

Fault detected

PCC opens; alarm rings

\section{Grid+ PV Mode}

$\mathrm{X}>=3 \mathrm{~V}, \mathrm{Y}>=3 \mathrm{~V}, \mathrm{Z}>=3 \mathrm{~V}$

Fault detected

PCC opens; alarm rings

\section{Hardware implementation}

Three phase fault analysis was conducted to determine the fault current using Simulink. Three sources have been considered for this protection scheme, namely, Grid connected source, PV1 and PV2.

The simulation results are used to formulate the algorithm to control the relay when the fault occurs in the system. Following approximations are made to build the code prototype

\section{Mode}

\section{Fault current}

1. Grid Connected $1500 \mathrm{~A}$

2. Islanded (PV1+PV2)

$$
2250 \mathrm{~A}
$$

3. Grid+PV1+PV2

$$
4500 \mathrm{~A}
$$

Based on these values of fault current, the reference voltage is set as $1 \mathrm{~V}$ for $1500 \mathrm{~A}$ and the corresponding voltage levels are calculated for each mode. Following is the table: 
Table 1

\begin{tabular}{|c|c|c|c|c|c|}
\hline $\mathrm{C}$ & GRID & PV1 & PV2 & SWITCH & MODE \\
\hline$X$ & $>=1 \mathrm{~V}$ & 0 & 0 & $\mathrm{ON}$ & Grid \\
\hline $\mathrm{Y}$ & 0 & $>=1.5 \mathrm{~V}$ & $>=1.5 \mathrm{~V}$ & $\mathrm{ON}$ & Islanded \\
\hline $\mathrm{Z}$ & $>=3 \mathrm{~V}$ & $>=3 \mathrm{~V}$ & $>=3 \mathrm{~V}$ & $\mathrm{ON}$ & Grid+PV \\
\hline
\end{tabular}

Two Bluetooth modules are employed for communication between the two Arduino Uno microcontrollers. The first microcontroller examines the current level to check for the fault current condition at various modes of operation and consequently conveys the status (STATUS $=1->$ Fault current $=\mathrm{HIGH}$; STATUS $=0 \rightarrow$ Fault current $=$ LOW) to the second microcontroller via Bluetooth modules (HC-05).

Depending upon the status received by second microcontroller, the relay is tripped and alarm rings. Wireless communication is used to convey the fault current status from the first Arduino UNO to the second. Following are the steps followed for communication:

Step 1: Pairing of master- slave Bluetooth modules using AT commands.

AT+ROLE

AT+ADDR

$\mathrm{AT}+\mathrm{CMODE}$

The ROLE OF Master and Slave modules are 1 and 0 respectively.

The modes of both modules are kept same for pairing them.

Step 2: Software Serial library has been imported to the arduino software. The various commands of this library are used for the wireless communication between the master and slave modules.

Test Results

The paper proposes an adaptive protection scheme for microgrids. The set up responds rapidly to the dynamic current conditions which arise due to the different modes of connection. The protection scheme acts accordingly to the different values of fault current. The data is transferred from one microcontroller to another via wireless communication. The data is then processed by the microcontroller for the indication of fault.

\section{Simulation results}

Following results have been obtained from the three-phase fault analysis:

Table 2

\begin{tabular}{|l|l|l|l|}
\hline $\begin{array}{l}\text { Mode of } \\
\text { connection }\end{array}$ & Set Voltage & Fault current(A) & Voltage(kv) \\
\hline $\begin{array}{l}\text { Grid connected (1 } \\
\text { source) }\end{array}$ & $11 \mathrm{kv}$ & 1408 & 1.93 \\
\hline $\begin{array}{l}\text { Islanded (2 } \\
\text { sources) }\end{array}$ & $11 \mathrm{kv}$ & 2816 & 3.8 \\
\hline $\begin{array}{l}\text { Grid+PV (3 } \\
\text { sources) }\end{array}$ & $11 \mathrm{kv}$ & 4224 & 5.81 \\
\hline
\end{tabular}

\section{Simulation inferences}

- The fault current increases with the addition of DER's.

- The voltage level increases with the increase in number of sources.

- Proportional voltages are considered to program the relay settings.

- Results of Simulation are used to make the analytical calculations.

\section{Analytical results}

Depending on the modes of connection and their corresponding fault currents the STATUS becomes 0 (LOW) or 1 (HIGH). Based on the STATUS value microntroller indicates the fault.
Table 3

\begin{tabular}{|l|l|l|}
\hline MODE & FAULT CURRENT & STATUS \\
\hline Grid Connected & $>=1500 \mathrm{~A}$ & 1 \\
\hline Islanded (PV1+PV2) & $>=2250 \mathrm{~A}$ & 1 \\
\hline Grid+PV1+PV2 & $>=4500 \mathrm{~A}$ & 1 \\
\hline
\end{tabular}

\section{Hardware results}

The set up switches between different modes of connection automatically depending upon the voltage values of the three sources.

- When Grid source(X) is supplying power and other two sources are at $0 \mathrm{~V}$ then system enters into the grid connected mode.

- When PV1 (Y) and PV2 (Z) are supplying power and grid source $(\mathrm{X})$ is at $0 \mathrm{~V}$ then system enters into the islanded mode.

- When Grid source(X), PV1(Y) and PV2 (Z) are supplying power then system enters into the Grid+PV mode.

\section{Grid connected mode}

When Grid source is greater than $1 \mathrm{~V}$, a fault current of $1500 \mathrm{~A}$ is detected. The fault signal is then transferred to the relay through wireless communication which makes the alarm set to ring.

\section{Islanded mode}

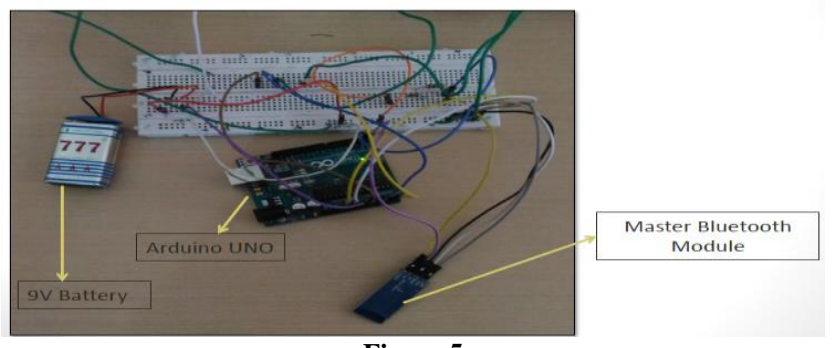

Figure 5

When both PV1 and PV2 source are greater than $1.5 \mathrm{~V}$, a fault current of $2250 \mathrm{~A}$ is detected. The fault signal is then transferred to the relay through wireless communication which makes the alarm set to ring.

\section{Grid+PV mode}

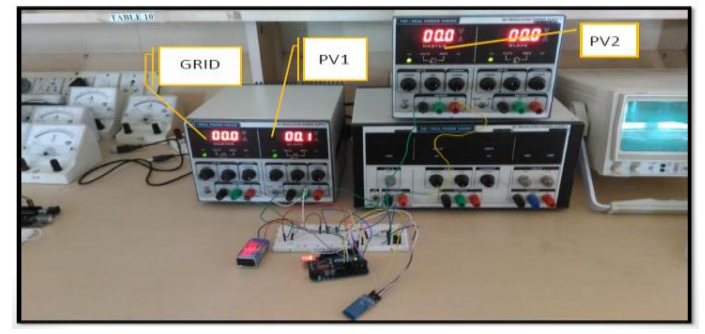

Figure 6

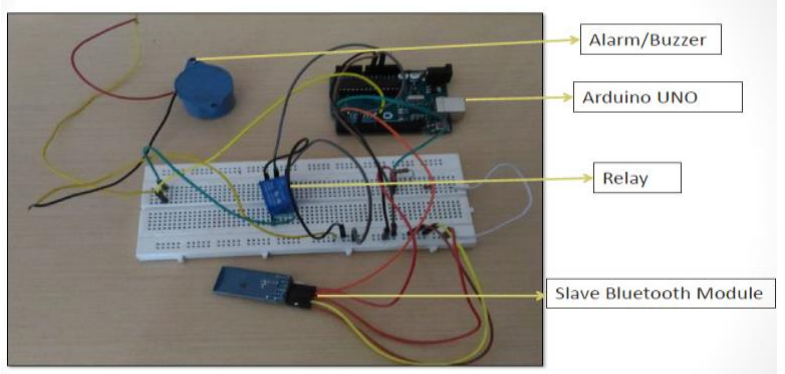

Figure 7 
When Grid, PV1 and PV2 source are greater than 3V, a fault current of 2250A is detected. The fault signal is then transferred to the relay through wireless communication which makes the alarm set to ring.

\section{Conclusion}

This adaptive protection scheme responds rapidly to the dynamic current conditions. Dynamic current condition arises due to the different modes of connection. Three phase fault analysis in Simulink determines the three phase fault currents in different modes of connection. Simulation results have been used for performing the analytical calculations. The algorithm is then prepared from the formulated equations.

The hardware setup comprised of two modules that are, master circuit and slave circuit. The master circuit included three sources, microcontroller and master Bluetooth module. The voltage value of the three sources is loaded in the microcontroller.The set up switches between different modes of connection automatically depending upon the voltage values of the three sources. These values are used to calculate the fault current. The corresponding fault current values are communicated from master bluetooth module to slave bluetooth module. The slave circuit included the microcontroller, slave Bluetooth module, relay and an alarm. The two bluetooth modules are paired. The communicated data to the slave Bluetooth module is processed by the microcontroller. The fault is indicated by the tripping of the relay and further ringing of the alarm.

\section{References}

[1] Hou D \& Dolezilek D, "IEC 61850-what it can and cannot offer to traditional protection schemes", Schweitzer Engineering Laboratories, Inc, 20080912, (2008).

[2] Eissa MM \& Abdel-Latif KM, "Factors Affecting on the Next Generation Protection on Smart Grid based on Wi-Fi Wireless Technology", IEEE International Conference on Smart Grid Engineering (SGE'12), (2012), pp. 1-8.

[3] Li H , Li H , Luo M \& Monti A, 'FerdinandaPonci, Design of Smart MVDC Power Grid Protection”, IEEE Transactions on Instrumentation and Measurement, Vol.60, No.9,(2011), pp. 3035 3046.

[4] Eissa MM, "New Protection philosophy for protecting Complex Smart Grid With Renewable Resources Penetration", IEEE International Conference on Smart Grid Engineering (SGE'12), (2012), pp .1-7.

[5] Khan RH, Brown J \& Khan JY, "Pilot protection schemes over a multi-service WiMAX network in the smart grid", IEEE International Conference on Communications Workshops (ICC), (2013), pp. 994-999.

[6] Bindu VS, Prabha MSRDM, "A survey on control and communication of smart grid", Indian Journal of Science and Technology, Vol.8, No.25,(2015), pp. 5-20.

[7] Zhang Z, Li H, Song JB, Han Z, Luo L \& Hu W, "Wireless Communication Aided Differential Relay Protection in Smart Grids: A Concerted Blitzkrieg", IEEE SmartGridComm Symposium - Communication Networks for Smart Grids and Smart Metering, Vancouver, (2013), pp. 330-335.

[8] Kamal A, Sankar S \& Soundarapandian R, "Optimal Overcurrent relay coordination of real time distribution system with embedded renewable generation", Indian Journal of Science and Technology , Vol.7, No.7,(2014), pp. 1-7.

[9] Fang X, Misra S, Xue G \& Yang D, "Smart Grid-The New and Improved Power Grid: A Survey", IEEE Communications Surveys \& Tutorials Fourth Quarter, Vol.14, No.4,(2012), pp. 944-980.

[10] Zareen N \& Mustafa MW, "Real-time energy imbalance management scheme for electric vehicles in the smart grid", Indian Journal of Science and Technology, Vol.8, No.3,(2015), pp.1-12. 